\title{
Diagnosis of Pulmonary Tuberculosis Using Genotype MTBDRplus Assay in Three Local Government Primary Health Centres of Osun State, Nigeria- a Pilot Study
}

\author{
Aderemi Oludiran Kehinde ${ }^{1 *}$ and Adetayo Emmanuel Adetoye ${ }^{2}$ \\ ${ }^{1}$ Department of Medical Microbiology and Parasitology, College of Medicine, University of Ibadan, Nigeria \\ ${ }^{2}$ Department of Microbiology, Faculty of Science, University of Ibadan, Nigeria
}

\begin{abstract}
Study background: Tuberculosis including multi-drug resistant form is not adequately diagnosed in spite of the fact that it constitutes a major public health challenge. This study was carried out to obtain data on laboratory diagnosis of pulmonary tuberculosis at the three local government areas in Osun state, Nigeria.

Methods: Six month pilot study was carried out at Iwo, Irewole and Ede North LGAs, all located in Osun state, Nigeria. Socio-demographic and clinical information of the subjects were obtained using a pre-tested questionnaire. Sputum samples were collected from symptomatic pulmonary tuberculosis patients, stained with Zeihl-Neelsen (Z$\mathrm{N}$ ) reagents and cultured on egg-based Lowenstein-Jensen medium. The medium was incubated at $37^{\circ} \mathrm{C}$ for eight weeks. Acid Fast Bacilli was confirmed by repeat Z-N staining. Drug resistance testing of the isolates was done using Genotype MTBDRplus. Serum was screened for HIV test using recombinant ELISA. Those that were screened positive were retested using Capillus HIV 1 and 2.

Results: Of the 75 subjects studied, seven $(9.3 \%)$ were over 60 years while the majority, $45(76.0 \%)$ were aged 21-60 years. Thirty-four (45.3\%) had their sputum positive for acid fast bacilli (AFB) while $24(32.0 \%)$ were culture positive. Among the 24 isolates, 6 were identified to be non tuberculos mycobacteria (NTM) by molecular methods. The HIV prevalence rate was observed to be $18.6 \%$ among all the study participants. Six out of 34 AFB positive persons $(17.6 \%)$ were also positive for HIV specific antibody, while eight $(19.5 \%)$ of the AFB negative persons were positive for HIV. There is no significant difference in the incidence of TB between the HIV infected and uninfected groups ( $p>0.05)$.Among the 18 mycobacterial isolates (excluding NTM), one strain (5.5\%) was found to be resistant to rifampicin and isoniazid (Multi-Drug Resistant-MDR) while three were resistant to isoniazid alone.
\end{abstract}

Conclusion: This pilot study reveals the existence of MDR-TB and warrants well designed studies to ascertain the magnitude of the problem.

Keywords: Tuberculosis; Multi-drug resistant; Osun state; Nigeria

\section{Introduction}

Tuberculosis (TB) continues to be a major threat worldwide despite the existence of antituberculosis drugs for the past 60 years [1]. About $80 \%$ of the estimated 9.4 million, new TB cases arising each year occur amongst the 22 countries with the highest global TB burden [1]. With an incidence of 460 smear positive TB cases per 100,000 inhabitants in 2009, Nigeria ranks fourth among these countries [2]. The TB burden in Nigeria is further strengthened by the relative high prevalence of HIV co-infection; as according to the World Health Organization (WHO) [2], about $18 \%$ of all TB patients tested were positive for HIV.

Certain important milestones are paramount in the fight to stop the spread of TB globally. These include: early diagnosis, prevention of the spread of the disease, effective treatment with anti-TB drugs and prevention of development of multidrug-resistant bacteria strains. In Nigeria as well as other high burden countries, these milestones have not been adequately addressed $[1,3]$. Thus, quick and reliable identification of the causative organism and early detection of drug-resistant strains are prerequisites to the effective treatment and confinement of the disease.

The primary diagnostic tool in most of the disease endemic countries remain smear microscopy with few centers having capacity for culture with little or no facilities for drug resistant testing [4,5]. Among the countries in sub-Saharan Africa with high burden of the disease, only few had national surveillance data on MDR-TB [2]. In Nigeria, information on the burden of MDR-TB especially in relation to risk factor like HIV infection is not readily available. Thus this study was carried out to provide preliminary data on MDR-TB in three local government areas in Osun state.

\section{Materials and Methods}

This six month cross sectional epidemiological study (JanuaryJune, 2011) was carried out at three designated DOTS centers in three Local Government primary health centers in Osun state (Iwo, Irewole and Ede North); the TB laboratory of the University College Hospital (UCH), Ibadan and the TB laboratory of the Nigerian Institute for Medical Research (NIMR), Lagos, Nigeria.

The three LGAs studied have a population of about one million [6] The TB laboratory in UCH is a designated facility for isolation of Mycobacterium Tuberculosis Complex (MTBC) in the Southwestern part of

*Corresponding author: AO Kehinde, TB unit, Department of Medical Microbiology and Parasitology, College of Medicine, University College Hospital, University of Ibadan, Nigeria, Tel: 234-8055203928; E-mail: aokehinde@yahoo.com

Received March 24, 2012; Accepted April 14, 2012; Published April 18, 2012

Citation: Kehinde AO, Adetoye AE (2012) Diagnosis of Pulmonary Tuberculosis Using Genotype MTBDRplus Assay in Three Local Government Primary Health Centres of Osun State, Nigeria- a Pilot Study. J Med Microb Diagn S3:001. doi:10.4172/2161-0703.S3-001

Copyright: (c) 2012 Kehinde AO, et al. This is an open-access article distributed under the terms of the Creative Commons Attribution License, which permits unrestricted use, distribution, and reproduction in any medium, provided the original author and source are credited. 
Citation: Kehinde AO, Adetoye AE (2012) Diagnosis of Pulmonary Tuberculosis Using Genotype MTBDRplus Assay in Three Local Government Primary Health Centres of Osun State, Nigeria- a Pilot Study. J Med Microb Diagn S3:001. doi:10.4172/2161-0703.S3-001

Page 2 of 4

the country while TB laboratory in NIMR serves as National TB reference Laboratory with capacity for detection of MDR-TB.

Of the 105 subjects recruited, only 75 (71.4\%) gave their consent and participated in the study. The study protocol was approved by the Ministry of Health, Osun state. Verbal and written consent was obtained from the subjects before enrollment into the study. Those who refused to give written consent were excluded.

Socio demographic characteristics and medical history of the subjects were obtained by questionnaire.

\section{Laboratory Investigations}

\section{Smear microscopy and Culture on solid media}

Two sputum specimens (on the spot and early morning) were collected from each of the clinically diagnosed confirmed pulmonary $\mathrm{TB}$ patients. The specimens were transported to the TB laboratory, UCH for immediate processing. Each sample was smeared, air-dried, fixed and stained with Zeihl-Neelsen (Z-N) reagents. A known positive Acid Fast Bacilli (AFB) and slide stained with egg albumin were used as positive and negative controls respectively. The results were read according to the grading system of the International Union against TB and Lung diseases [7].

For isolation of the organism, sputum was decontaminated using N-Acetyl L-cysteine /Sodium Hydroxide (NALC/NaOH) method [8]. The resulting solution was mixed by vortex mixer. About one $\mathrm{ml}$ from the mixture was inoculated onto freshly prepared Lowenstein-Jensen (LJ) medium, incubated at $37^{\circ} \mathrm{C}$ for eight weeks. M. tuberculosis strain $\mathrm{H} 37 \mathrm{Rv}$ and sterile LJ medium were used as positive and negative controls respectively. Evidence of contamination was determined by looking out for growth before two weeks of incubation while suspicious isolates were confirmed by colonial morphology, Z N reaction and standard biochemical tests [9]. Patients revealed the presence of AFB by smear or cultures were referred to the chest physician for management.

\section{Drug resistance testing}

The culture isolates were subjected to further confirmation as $\mathrm{MTBC}$ and then drug resistance testing to rifampicin and isoniazid using Genotype MTBDRplus (HAIN Lifescience, GmbH, Germany). The entire technique was divided into three parts namely: DNA extraction from positive isolates on LJ slope, PCR amplification and hybridization using MTBDRplus dedicated incubator. The entire procedure was carried out according to the manufacturers' instructions [10].

\section{HIV testing}

About $5 \mathrm{ml}$ of venous blood was collected from each subject. Serum was screened for HIV using recombinant ELISA kit (Human Biochemical and Diagnostic Laboratories, Germany). Those that were screened positive were retested using Capillus HIV 1 and 2 (Cambridge diagnostic). Positive ones were appropriately counseled and referred to the nearest antiretroviral center for management.

\section{Data analysis}

Data was coded and analyzed using statistical software SPSS version 10.0 (SPSS Inc, Chicago, IL, USA). Frequency tables were used to describe demographic characteristics and laboratory variables while Chi square test was used to measure the association between categorical variables.

\section{Results}

\section{Demographic characteristics}

Consent was sought from 105 participants, of whom 75 subjects (71.4\%) gave consent and participated in the study giving a male to female ratio of 0.80 to 1.00 respectively. Only seven (9.3\%) were over 60 years while the majority (76.0\%) were aged 21-60 years. Of the 75 subjects, six $(8.0 \%)$ were professionals while 10 (13.3\%) were unemployed (Table 1).

\section{Laboratory data}

Thirty-four (45.3\%) of the 75 subjects had their sputum samples positive for AFB on smear microscopy while 41 (54.7\%) were negative. Twenty four (32.0\%) samples were positive by culture, 48 (64.0\%) were negative while three $(4.0 \%)$ were contaminants.

Among the study participants, 24 (32.0\%) were positive for both smear microscopy and culture while $24.0 \%$ were smear negative but positive for culture (Table 2). Prevalence of HIV positivity among the study population was 14 (18.6\%). Of the 34 subjects with smear positive samples, six (17.6\%) were HIV positive while eight (19.5\%) out of the 41 smear negative ones were positive for HIV. There was no HIV difference ( $p>0.05)$. Large proportions of subjects with smear negative and culture positive samples and those with only positive culture samples were also HIV positive (33.3\%) (Table 2).

Of the 24 isolates tested for drug resistance, one (5.5\%) was found

\begin{tabular}{|c|c|c|c|c|}
\hline \multirow[b]{2}{*}{ Variable } & \multicolumn{4}{|c|}{ Sex } \\
\hline & & $\begin{array}{l}\text { Male } \\
\text { No (\%) }\end{array}$ & $\begin{array}{c}\text { Female } \\
\text { No(\%) }\end{array}$ & $\begin{array}{l}\text { Total } \\
\text { No (\%) }\end{array}$ \\
\hline \multicolumn{5}{|l|}{ Age (yr) } \\
\hline$<20$ & 09 & $(42.9 \%)$ & $12(57.1 \%)$ & $21(100.0 \%)$ \\
\hline $21-40$ & 11 & $(47.8 \%)$ & $23 \quad(52.2 \%)$ & $34(100.0 \%)$ \\
\hline $41-60$ & 10 & $(76.9 \%)$ & $03 \quad(23.1 \%)$ & $13(100.0 \%)$ \\
\hline$>60$ & 02 & $(28.6 \%)$ & $05 \quad(71.4 \%)$ & $07(100.0 \%)$ \\
\hline Total & 32 & $(42.7 \%)$ & $43 \quad(57.3 \%)$ & $75(100.0 \%)$ \\
\hline \multicolumn{5}{|c|}{ Occupational status } \\
\hline Professionals & 02 & $(33.3 \%)$ & $04 \quad(66.7 \%)$ & $06(100.0 \%)$ \\
\hline Skilled & 05 & $(83.3 \%)$ & $01 \quad(16.7 \%)$ & $06(100.0 \%)$ \\
\hline Unskilled & 20 & $(37.7 \%)$ & $33(62.3 \%)$ & $53(100.0 \%)$ \\
\hline Unemployed & 07 & $(70.0 \%)$ & $03(30.0 \%)$ & $30(100.0 \%)$ \\
\hline Total & 34 & $(45.3 \%)$ & $41(54.7 \%)$ & 75 \\
\hline
\end{tabular}

Table 1: Demographic characteristics of study subjects by sex.

\begin{tabular}{|c|c|c|}
\hline Test & $\begin{array}{l}\text { Result } \\
\text { No } \quad(\%)\end{array}$ & $\begin{array}{l}\text { HIV positivity } \\
\text { No }(\%)\end{array}$ \\
\hline $\begin{array}{l}\text { Smear Microscopy } \\
\text { Positive } \\
\text { Negative } \\
\text { Total } \\
\end{array}$ & $\begin{array}{lc}34 & (45.3 \%) \\
41 & (54.7 \%) \\
75 & (100.0 \%)\end{array}$ & $\begin{array}{ll}06 & (17.6 \%) \\
08 & (19.5 \%) \\
14 & (18.6 \%) \\
\end{array}$ \\
\hline \begin{tabular}{|l|} 
Culture \\
Positive \\
Negative \\
Contaminant \\
Total \\
\end{tabular} & $\begin{array}{ll}24 & (32.0 \%) \\
48 & (64.0 \%) \\
03 & (4.0 \%) \\
75 & (100.0 \%)\end{array}$ & $\begin{array}{ll}08 & (33.3 \%) \\
04 & (8.3 \%) \\
02 & (66.7 \%) \\
14 & (18.6 \%)\end{array}$ \\
\hline $\begin{array}{l}\text { Combined Smear and Culture } \\
\text { Smear positive Culture positive } \\
\text { Smear negative Culture negative } \\
\text { Smear positive Culture negative } \\
\text { Smear negative Culture positive } \\
\text { Total }\end{array}$ & $\begin{array}{ll}24 & (32.0 \%) \\
23 & (30.7 \%) \\
10 & (13.3 \%) \\
18 & (24.0 \%) \\
75 & (100.0 \%)\end{array}$ & $\begin{array}{ll}06 & (25.0 \%) \\
01 & (4.3 \%) \\
01 & (4.3 \%) \\
06 & (33.3 \%) \\
14 & (18.6 \%)\end{array}$ \\
\hline
\end{tabular}

Table2: Smear microscopy and culture results by HIV seropositivity. 
Citation: Kehinde AO, Adetoye AE (2012) Diagnosis of Pulmonary Tuberculosis Using Genotype MTBDRplus Assay in Three Local Government Primary Health Centres of Osun State, Nigeria- a Pilot Study. J Med Microb Diagn S3:001. doi:10.4172/2161-0703.S3-001

to be MDR-TB, three (16.7\%) showed mono resistance to isoniazid while one (5.5\%) was inconclusive. Six $(25.0 \%)$ were Non Tuberculosis Mycobacteria (NTM) (Figure 1).

\section{Discussion}

Globally, ineffective TB detection and rise of drug resistant strains in the presence of high prevalence of HIV infection have led to calls for dramatic expansion of laboratory diagnostic capacities in countries where the two diseases are endemic $[2,11]$. Majority of the study subjects $(76 \%)$ were in middle age group. This is in agreement with findings from other studies showing that TB predominately affects patients who are in their productive age [12-14]. This study's positivity rate of $45.3 \%$ for smear microscopy and $32.0 \%$ for culture were higher than what were earlier reported in this center $[15,16]$. This might be attributed to the fact that the study populations were symptomatic PTB subjects as against asymptomatic health care workers screened in the two previous studies $[15,16]$. Moreover, the subjects were recruited directly from their communities through the nearest primary health centers unlike the previous studies which were hospital based.

Fourteen $(18.6 \%)$ of the subjects were HIV positive. This figure compares favorably with the national statistics of $21 \%$ [2]. This implies that DOTS centers can serve as an important entry point for HIV diagnosis, care and support. A significant percentage of subjects with culture positive samples were also HIV positive (Table 2). This further reinforce the fact that $\mathrm{TB}$ is one of the most common opportunistic infections among HIV-infected individuals, and co-infected individuals are at high risk of death $[17,18]$. Coordination and cross-talk between

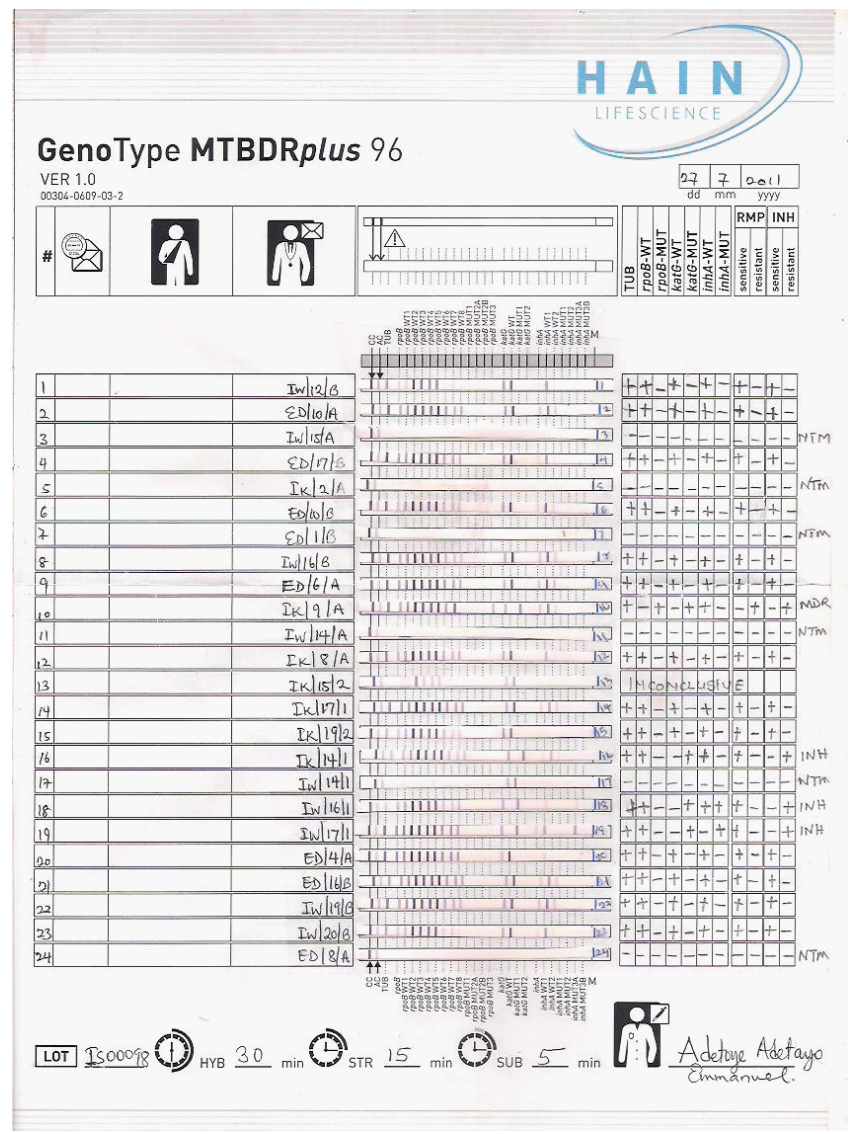

Figure 1: Drug susceptibility results. the two national health programmes are crucial not only to improve the outcome of HIV-infected TB patients but also to control the burden of TB in Nigeria. Those subjects who had their samples negative on smear microscopy but positive for culture present a great diagnostic challenge to the National TB Control Programme as culture facilities are only available in few centers in the country. These are most likely TB/HIV co-infected subjects (Table 2).

Inability to do chest radiography examinations is one of the limitations of the study. This was due to financial constraints. Chest $\mathrm{X}$ ray may appear normal in $7-14 \%$ of patients with HIV/TB co-infections $[19,20]$, and at the same time miss a substantial proportion of individuals with sub -clinical disease, often seen in advanced HIV immunosuppression $[1,22]$.

Seventy five percent of the isolates were confirmed as MTBC while six (25.0\%) were NTM. The MTBC comprises M. tuberculosis, M.africanum and M. bovis. These three mycobacteria species are AFB and indistinguishable by smear microscopy which is the WHO diagnostic tool available in most of the disease endemic countries including Nigeria. The need to employ molecular typing tool to distinguish between members of MTBC cannot be over emphasized because some species may be associated with serious diseases in humans [23].

About three quarter (72.2\%) of the MTBC isolates were susceptible to isoniazid and rifampicin while one was resistant to both drugs (MDR-TB isolate). The exact cause of the emergence of this MDR strain is unknown; however; poor drug compliance could be a possible reason.

The findings of this study show that MDR-TB is present in Osun state. This necessitates a well design study to ascertain the actual burden of MDR-TB in the community.

\section{Acknowledgement}

The authors acknowledge with thanks to the technical support of the medical laboratory scientists at the TB Laboratory, University College Hospital, Ibadan and also staff at the National TB reference Laboratory Nigerian Institute for Medical Research, Lagos, Nigeria. The staff and patients at the three LGAs are also acknowledged.

\section{References}

1. World Health Organization (2011) Global tuberculosis control: surveillance, and financing. WHO report, Geneva.

2. World Health Organization (2010) Global tuberculosis control: surveillance, and financing. WHO report, Geneva.

3. Grange JM, Zumla A (2002) The global emergency of tuberculosis: what is the cause? J R Soc Promot Health 122: 78-81.

4. Kehinde AO, Obaseki FA, Cadmus SI, Bakare RA (2005) Diagnosis of tuberculosis: urgent need to strengthen laboratory services. J Natl Med Assoc 97 394-396.

5. Boehme CC, Nabeta P, Hillemann D, Nicol MP, Shenai S, et al. (2010) Rapid molecular detection of tuberculosis and rifampin resistance. N Engl J Med 363 1005-1015.

6. Federal Republic of Nigeria Official Gazette (2009) Legal notice of publication of 2006 census final results. Abuja, Nigeria: Federal Government of Nigeria 2: 38-39.

7. Enarson DA (2000) Laboratory diagnosis of pulmonary tuberculosis. Management of tuberculosis. A guide for low income countries. (5thedn), International Union Against Tuberculosis and Lung Diseases. Paris

8. Kent PT, Kubica GP (1985) Public health mycobacteriology. A guide for the level 111 laboratory. Centers for Disease Control and Prevention. Atlanta, USA

9. Barrow GI, Feltham RKA (1995) Cowan and Steel's Manual for the Identification of Medical Bacteria. (3rdedn), Cambridge University Press, Cambridge. 
Citation: Kehinde AO, Adetoye AE (2012) Diagnosis of Pulmonary Tuberculosis Using Genotype MTBDRplus Assay in Three Local Government Primary Health Centres of Osun State, Nigeria- a Pilot Study. J Med Microb Diagn S3:001. doi:10.4172/2161-0703.S3-001

10. HAIN Lifescience GmbH. Rapid diagnosis of tuberculosis, mycobacteriosis and Leprosy. www.hain-lifescience.de

11. Ige OM, Sogaolu OM, Ogunlade OA (2005) Pattern of presentation of tuberculosis and the hospital prevalence of tuberculosis and HIV co-infection in University College Hospital, Ibadan: a review of five years (1998-2002). Afr J Med Med Sci 34: 329-333.

12. Erhabor GE, Adebayo RA, Omodara JA (2003) Ten year review of pattern of presentation and outcome of pulmonary TB in OAUTHC, lle-Ife, Nigeria. Nig J of Health Sciences 3: 34-37

13. Sutherland I (1976) Recent studies in the epidemiology of tuberculosis based on the risk of being infected with tubercle bacilli. Adv Tuberc Res 19: 1-63.

14. Kehinde AO, Ige OM, Dada-Adegbola HO, Obaseki FA, Ishola OCO (2006) Pulmonary tuberculosis in Ibadan: a ten year review of laboratory reports (19962005). Afr J Med Med Sci 35: 475-478.

15. Kehinde AO, Baba A, Bakare RA, Ige OM, Gbadeyanka CF, et al. (2010) Risk factors for pulmonary tuberculosis among health-care workers in Ibadan, Nigeria. Afr J Med \& Med Sci 39: 105-112.

16. Kehinde AO, Baba A, Bakare RA, Ige OM, Gbadeyanka CF, et al. (2011) Pulmonary tuberculosis among health care workers at two designated DOTS centers in urban city of Ibadan, Nigeria. Indian J Med Res 133: 613-617.

17. Corbett EL, Watt CJ, Walker N, Maher D, Williams BG, et al. (2003) The growing burden of tuberculosis: global trends and interactions with the HIV epidemic. Arch Intern Med 163: 1009-1021.
18. Lawan SD, Churchyard G (2009) Epidemiology of HIV associated tuberculosis. Curr Opin HIV AIDS 4: 325-333.

19. Post FA, Wood R, Pillay GP (1995) Pulmonary tuberculosis in HIV infection: radiographic appearance is related to $\mathrm{CD} 4+\mathrm{T}$-lymphocyte count. Tuber Lung Dis 76 : $518-521$.

20. Swaminathan S, Narendran G, Menon PA, Padmapriyadarsini C, Arunkumar $\mathrm{N}$, et al. (2007) Impact of HIV infection on radiographic features in patients with pulmonary tuberculosis. Indian J Chest Dis Allied Sci 49: 133-136.

21. Churchyard GJ, Fielding KL, Lewis JJ, Chihota VN, Hanifa Y, et al. (2010) Symptom and chest radiographic screening for infectious tuberculosis prior to starting isoniazid preventive therapy: yield and proportion missed at screening. AIDS 5: S19-S27.

22. Padmapriyadarsini C, Narendran G, Swaminathan S (2011) Diagnosis and treatment of tuberculosis in HIV co-infected patients. Indian J Med Res 134 850-865.

23. Allix-Beguec C, Fauville-Dufaux M, Stoffels K, Ommeslag D, Walravens K, et al. (2010) Importance of identifying Mycobacterium bovis as a causative agent of human tuberculosis. Euro Respir J 35: 692-694.

24. Kehinde AO, Obaseki FA, Ishola OC, Ibrahim KD (2007) Multidrug resistance to Mycobacterium tuberculosis in a tertiary hospital. J Natl Med Assoc 99 1185-1189.
This article was originally published in a special issue, Clinical Diagnostic Microbiology handled by Editor(s). Dr. KM. Mythreyee, MGR University, India 